\title{
Early evolution of neurological surgery: conquering increased intracranial pressure, infection, and blood loss
}

\author{
Jennifer R. Voorhees, B.A., Aaron A. Cohen-Gadol, M.D., \\ AND DENNIS D. SPENCER, M.D. \\ Department of Neurological Surgery, Yale University School of Medicine, New Haven, Connecticut; \\ and Department of Neurologic Surgery, Mayo Clinic and Mayo Foundation, Rochester, Minnesota
}

\begin{abstract}
At the end of the 19th century, the early evolution of the specialty of neurological surgery was restricted by complications related to infection, increased intracranial pressure, and excessive intraoperative blood loss. These complications often caused mortality rates of 30 to $50 \%$. An improved understanding of pathophysiological factors involved in increased intracranial pressure, along with meticulous surgical techniques learned from William Halsted, allowed Harvey Cushing to increase the safety of neurosurgical procedures that were then in their infancy. Cushing's later development of the "silver clip" and incorporation of electrosurgical techniques facilitated safe resection of brain tumors previously assumed to be inoperable. These pivotal accomplishments paved the way for the establishment of our specialty.
\end{abstract}

\section{KEY Words - Harvey Cushing • hemostasis • infection - intracranial pressure • history of neurosurgery}

Harvey Williams Cushing was born in the Western Reserve, Ohio, on April 8, 1869. His father, Dr. Henry Kirke Cushing, had taken over the local medical practice of his own father, Erastus Cushing. Erastus' father, David Cushing, was the first Cushing physician and had practiced back East in Boston. Although Harvey was part of a long line of Cushing doctors, his future was not predetermined, and his path to the esteemed position in the medical world that he eventually earned did not lie along the straight and narrow. Harvey's outside interests, his curiosity, and his artistic side were important to his success as a physician, along with the sense of compassion he acquired from his strong family ties. Several formative events from his youth were relevant to the making of a physician who would establish a new specialty.

\section{THE MAKING OF A MAN}

\section{Harvey Cushing's Formative Years}

As a boy, Harvey's interests in sports and natural history dominated him. He was a natural at gymnastics, and, ironically, it was after an accident at the YMCA in 1884, during his sophomore year of high school, that Harvey had his first experience with the healing process and with his father as a doctor. Harvey broke his wrist after slipping from a turning bar, and he feared his father's reprimand almost more than he felt the pain of his injury. Elizabeth Thomson described Harvey's subsequent enthrallment with what happened instead. "To his surprise, his father said nothing at all but set the bone and fixed the splint with infinite care and gentleness. So fascinated was Harvey by the whole operation that he scarcely felt the pain, and in the days that followed, his interest in the mending process considerably mitigated a boy's natural impatience with a temporarily useless arm." "As his father's patient, Harvey gained a new perspective, and it is likely that this first impression stayed with him over the years.

In the same year, Cushing came under the influence of a high school physics teacher, Newton Anderson. Anderson taught Cushing and his peers discipline and dexterity through summer voyages on the Great Lakes. As Thomson explained, Anderson "understood boys and possessed the native talents which they admired." ${ }^{\text {F }}$ Fulton stated that Cushing's contemporaries from Cleveland ascribed his success as a surgeon in part to Anderson's influence. One of the boys recalled of Anderson, "He taught us a lot about being independent and made us so by the duties he inflicted upon us during these summer vacations. We were all undoubtedly better disciplined and better prepared for life from the teachings of this man and from the association such as we had with him." 4 As Cushing himself said, "We embryo carpenters progressed to a course on wood-turning with lathes and a year later to metal work at a forge like so many blacksmiths learning to strike when the iron was hot - the best cure for youthful indecision." ${ }^{4}$ Anderson taught Cushing the value of discipline and was a role model as a teacher, another one of Harvey's important attributes later in life.

Cushing's election as president of his senior class reflected his congenial nature and leadership skills. Despite his gallivanting, he passed Yale's entrance exams, and his undergraduate pursuits indicated the exceptional man he 
was to become. He continued to recognize the value in nonacademic activities and had several tiffs with his father about his participation as shortstop on the baseball team and in various societies of students. His experience with the team reinforced discipline and also taught him the value of teamwork. Collaboration would be the key to success for many of his greatest accomplishments, none more so than with Bovie and electrosurgery later in his surgical career.

\section{Early Contributions to Medicine}

At Harvard Medical School, Cushing's resourcefulness, self-discipline, and ingenuity began to contribute directly to the medical world. During his clinical years he went well beyond the typical role of a student, serving in an emergency dispensary, as an anesthetist, and as a surgical assistant. As a second-year student, an adverse event made a lasting impression on Cushing, yet also led to his first major contribution to medicine. Dr. Frank Lyman had asked him to substitute for the regular staff member in the administering of anesthesia. Unfortunately, one of the first patients died on the table. Blaming himself, Cushing nearly quit medicine, but Dr. Lyman convinced him that it was not his fault.

Nonetheless, this incident made Cushing realize the inadequate methods of administering anesthesia and monitoring the patient. He subsequently developed ether charts with classmate Amory Codman as a system for continuous monitoring of the patient's pulse and respiration. ${ }^{4}$ In this way, by reducing the risk of an accidental overdose, Cushing made a relatively young technology, ether anesthesia, safer and more applicable in medicine. Perhaps medicine's greatest development in the 19th century was the use of ether anesthesia to conquer the pain of the surgeon's knife. William Morton first demonstrated its use in what is now the "Ether Dome" at Massachusetts General Hospital in 1846. Patients demanded ether even though physicians had reservations about its safety, and accidents occurred when unskilled practitioners used too much. Cushing's ether charts allowed for the safe use of this type of anesthesia, were readily adopted, and made the practice much safer.

His early support of the $\mathrm{x}$-ray cathode in 1896, just months after German physicist William Roentgen announced the discovery of x-rays, demonstrates Cushing's embrace of a promising new medical technology. Cushing contributed a portion of his own money toward Massachusetts General Hospital's first x-ray machine. He wrote home to his mother, "We have at last succeeded in having an X-ray machine put in for which I have subscribed largely and hope the conservative staff will ultimately remunerate us for it." 4 This occasion also marked Cushing's first experience of being at odds with Harvard's conservative staff, and he would later face similar experiences with the Riva-Rocci blood pressure machine and electrosurgery. Collaborating with Codman, Cushing helped to inaugurate the clinical use of x-rays. He was so personally committed to advancing their application that he brought the machine with him when he left Harvard and did all of the x-ray work for a time at the Johns Hopkins Hospital, where he performed his pivotal surgical residency. ${ }^{8}$

\section{Cushing's Johns Hopkins Residency}

In 1896 Cushing made the decision to perform his residency at Johns Hopkins, which, although a relatively young institution, had risen to a superior position in American medicine through its innovative educational model. The Johns Hopkins Hospital had opened in 1889 under the leadership of four bright young men: William Welch, trained in the German scientific tradition, as the nation's first full-time chair in pathology; William Halsted, meticulous surgeon, promising teacher, and dedicated researcher from Bellevue Medical College, as professor of surgery; William Osler, brilliant clinician and teacher from the University of Pennsylvania, as the chair of medicine; and Howard Kelly, excellent and innovative surgeon, also from University of Pennsylvania, as the chair of gynecology and obstetrics. ${ }^{8}$ Harvey's older brother Ned, also a physician, advised him regarding this decision, "of Halsted and the Johns Hopkins ... there is no surgeon like him in the land ... his aseptic technique is perfect ... the scientific manner of his work, keeping at it from the laboratory side simultaneously with his clinical and operative work, is a revelation to a man." considering traveling abroad after medical school, he recognized this opportunity to train under the best and 'struck while the iron was hot,' as his high school teacher Anderson had taught him.

Indeed, working under Halsted greatly influenced Cushing and strengthened him both as a surgeon and as a person. Cushing essentially relearned surgery from Halsted, who patiently approached it as an art, not a race, as was the general mentality of surgeons at the time. Cushing followed Halsted's example: a careful preliminary study of each case, painstaking operative technique, and close examination of the tissues in the laboratory afterward. ${ }^{8}$ Unfortunately, Halsted had experimented with cocaine as a local anesthetic agent while at Bellevue, and, unaware of its habit-forming tendencies, had used himself as the subject. Halsted fought the addiction but his health, both physically and mentally, was permanently compromised. ${ }^{8}$ Cushing's relationship with Halsted was somewhat strained by the latter's seemingly puzzling behavior and frequent absences from the clinic, but the independence and responsibility Cushing subsequently took on were crucial to his early development as a surgeon. In Halsted's absence, Cushing was able to do much more than a resident would normally be permitted and, especially toward the end of his residency, often ran the surgical service himself. ${ }^{8}$

\section{European Experiences}

Following his residency, Cushing planned a 14-month journey to Europe; it was customary, at the turn of the last century, for young American doctors to visit Europe and observe the traditionally superior practice of medicine there. Although Cushing's interest in the central nervous system had intensified at Hopkins, it was during his time abroad that he became intent on developing the field of neurological surgery. Accustomed to Halsted's relatively flawless methods, Cushing was less than impressed with many of the European surgeons he observed. The Swiss surgeon Theodor Kocher was one who lived up to Cush- 
ing's expectations, and through him Cushing gained a new surgical mentor and the research experience that forever linked him to the central nervous system. ${ }^{7}$

During his European travels, Cushing learned about the current status of operations on the brain and the major obstacles he would have to overcome to establish the specialty. In London, Cushing sought out Victor Horsley, the pioneering British neurosurgeon, and was disappointed with his technique. He wrote home to his father, "I am a little disappointed in Victor Horsley.... The technique of all these men is execrable from our standpoint and they must have many septic wounds." 8 At that time, Horsley and other neurosurgical pioneers experienced mortality rates of 30 to $50 \%$, the major cause of death being postoperative infection leading to cerebritis and meningitis. (Such an infection, referred to as "brain fungation," had taken the life of Bennett and Godlee's patient 29 days after their monumental operation.) Cushing undoubtedly perceived this obstacle as one that he could overcome with his superior operative techniques. Deciding that "the refinements of neurological surgery could not be learned from Horsley," Cushing decided to leave London. ${ }^{4}$

After visiting the surgical clinics of Jaboulay, Ollier, and Louis Dor in France, August Reverdin in Geneva, and Cesar Roux in Switzerland, Cushing settled in Bern, Switzerland, where he was finally thoroughly impressed by Kocher. In his diary he wrote, "but the operating! - the J.H.H. outdone.... Detailed technique, tedious operating, absolute hemostasis." Kocher placed Cushing in the research laboratory of Hugo Kronecker to study the effects of intracranial pressure on circulation. Cushing's finding, that "an increase of intracranial tension occasions a rise of blood pressure which tends to find a level slightly above that of the pressure exerted against the medulla," became known as the Cushing reflex. Cushing's devotion to this project and his ingenuity in obtaining results produced tangible findings that he planned to apply practically in surgery. Thus, Cushing's return to Hopkins became contingent on his being put in charge of the "neurological side of the Clinic." 4

As his European travels came to an end, Cushing came across another crucial technology that he embraced and introduced to the American medical community. In Pavia, Italy, Cushing observed Scipione Riva-Rocci using a device to measure blood pressure and immediately identified the utility of such an apparatus for monitoring patients during surgical procedures. He even remained an extra day to secure a model of the inflatable armlet to take back with him to the US. Although Cushing advocated its use and the addition of blood pressure readings on ether charts, a committee at Harvard ruled that a physician's skilled finger was better than such a device. Nevertheless, the utility of the blood pressure cuff was too great and readings became routine in medicine and surgery despite Harvard's conservatives. ${ }^{8}$

\section{REINVENTING NEUROSURGERY}

\section{Obstacles to Conquer}

After identifying the obstacles to successful neurological surgery, Cushing returned to Baltimore in 1901, determined to explore the potential for elimination of postoper- ative cerebral infection, the alleviation of the effects of increased intracranial pressure, and the monitoring of blood pressure during operations, in his efforts to decrease mortality rates. Massive blood loss was one of the main causes of death during surgery, along with meningitis. Because specific blood types and compatibility indications were not known, transfusion reactions occurred and were associated with significant side effects. Also, storage of blood was not possible, and finding a donor who would be available at the time of surgery was not an easy task. For these reasons, blood transfusions were done rarely. Cushing initially addressed the problem of blood loss indirectly by using the Riva-Rocci apparatus to keep track of blood pressure during operations. Knowledge of the patient's blood pressure signaled to Cushing when a transfusion was necessary or when to stop the operation. Therefore, with the means to monitor blood pressure, the surgical control of bleeding was not Cushing's primary focus between 1901 and 1910, "the crucial decade" in the development of neurosurgery. ${ }^{5}$

By 1905, Cushing had made substantial progress in reducing infection and relieving intracranial pressure associated with neurological surgery. As he had hoped, his careful technique had nearly eliminated the complication of infection. He declared, "Even to the painstaking final approximation of the scalp wound, every detail of the operation and of the local after-treatment must be followed out with the greatest care, if one wishes to avoid that most distressing of all complications, a fungus cerebri, which I am happy to say has occurred to me only twice." ${ }^{5}$ In this way, he was able to apply his laboratory findings on intracranial pressure to practical procedures.

Cushing popularized palliative subtemporal decompressions to alleviate increased intracranial pressure when tumor removal could not be attempted or accomplished. Subtemporal decompression existed before him, but he was the first to use this procedure primarily to relieve increased intracranial pressure. ${ }^{6} \mathrm{He}$ would often perform one or two separate decompression procedures to lower intracranial pressure before attempting tumor removal. In such cases, knowing that he would have to operate again soon, Cushing would take meticulous care to close the wound, including the galea, during these palliative decompressions. According to Horrax, ${ }^{6}$ this accomplishment was one of Cushing's favorites, and in later years when questioned about his surgical contributions he would reply, "Tell them that I closed the galea."

The methods of hemostasis Cushing used during this time were limited mainly by the anatomy he encountered while performing a cranial decompression. To control bleeding from the scalp, Cushing developed a pneumatic tourniquet in 1904. ${ }^{4}$ To minimize bleeding from the skull, he used Horsley's formula for antiseptic bone wax, a mixture of beeswax, salicylic acid, and almond oil.

Although Cushing had developed the necessary techniques by 1905 and was ready to devote himself completely to neurological surgery, he needed to recruit patients in his practice. He had seen only 29 neurosurgical patients (not just tumor patients) at that point, and because he had focused on palliative decompressions, he had not performed any successful tumor extirpations. ${ }^{5}$ For the next 5 years, he therefore concentrated on reporting his techni- 
cal accomplishments and the early symptoms of increased intracranial pressure-headache, vomiting, and papilledema. Cushing completed work on 74 publications during this decade and gave various presentations to colleagues in the medical field to increase referrals to his practice. ${ }^{5}$

As a result, by 1910 Cushing had the clinical statistics to document his progress. He had operated 250 times on 180 patients and had achieved a mortality rate of less than $13 \%$. Moreover, in his last 50 cases up to that date, he reported a mortality rate of less than $6 \% .^{5}$ As the only neurosurgeon to have substantially lowered his mortality rate, Cushing now looked ahead to the next obstacle.

Until 1926, his greatest limiting factor remained the control of bleeding during operations. Logically, "The Control of Bleeding in Operations for Brain Tumors" "2 was the title of Cushing's 1911 publication, which was sparked by the development of his first major weapon against blood loss from the brain, the "silver clip." By this time, because Cushing's meticulous operative techniques had enabled him to attack many tumors directly, the majority of his work involved direct contact with delicate brain tissue. Accepted mechanisms for controlling bleeding in general surgery, such as sutures or clamps, were not suitable for delicate brain tissue. In this way, procedures became longer and more tedious, and hemostasis became more important. The length of the procedures, which had to be delayed numerous times to deal with hemostasis, was a risk of its own. The amount of blood lost at any point in an operation would be doubled by the time the wound was properly closed, because it took as long for Cushing to get out as it did for him to get into the brain. Cushing described the danger of blood loss, "A more general loss of blood with the consequent lowering of arterial tension is a cordial invitation to near relative shock, favors the onset of respiratory paralysis in cases associated with medullary pressure and makes anesthesia more dangerous, and lowers resistance to infection through secondary anemia." 2 In addition, Cushing described the complications caused by bleeding during an operation, "Neighboring oozing obscures the clear view essential to the safety of such delicate manipulations as are required for the removal of, let us say, a lateral recess tumor or the trigeminal ganglion." 2 Blood loss was a major obstacle to the refinement of his techniques and success in complicated procedures.

By 1909, Cushing's innovative efforts were concentrated on hemostasis. He began to use bits of living tissue, either muscle from the exposed temporal region or fragments of partially organized blood clots, to facilitate hemostasis. ${ }^{6}$ These procedures were used in addition to the gauze pledgets with black ligature. Cushing's silver clips, devised in 1908 but not developed until 1910, were applied directly to vessels that were out of reach of the ligature. ${ }^{2}$ The fabrication and application of these clips consisted of wrapping silver wire around a grooved steel pencil, then cutting it to make U-shaped pieces, which were loaded onto a magazine to be picked up by the jaws of the holder. The first catch point held the wire without deforming it, and once the $U$ was flattened onto a vessel the holder would unlock itself. A similar clip is still in use today.

\section{New Opportunities at Harvard}

In 1912, Cushing returned to Harvard Medical School to assume the prestigious Mosley Professorship and the Chair of Surgery at the new Peter Bent Brigham Hospital. Cushing had entertained offers from other top programs, including Yale. Nevertheless, the Hopkins system had made him a firm believer in the need for a full-fledged hospital in which medical professors could practice, teach, and use clinical data in research. Cushing's priority was to have patients available to him so that he could continue his neurosurgical progress. Yale only had a dispensary, and Cushing wrote to President Arthur Hadley with the following critique: "The one pressing need of the School is a hospital with a continuous service for those occupying the clinical chairs ... without such a hospital a medical school can hardly be expected to develop." ${ }^{4}$ Harvard, on the other hand, allowed Cushing to participate significantly in the planning of the new hospital, which provided him with exactly what he wanted.

\section{Further Work on Hemostasis}

Although his job description broadened substantially, Cushing continued to develop his neurosurgical craft and to concentrate on his greatest obstacle: maintaining hemostasis in neurosurgical procedures. During World War I, the applicable properties of adrenaline as a vasoconstrictor were discovered, and Cushing subsequently abandoned his tourniquet in favor of scalp injections of adrenaline. This method, along with the hanging of weighted pendant hemostats, provided enough tension to stop bleeding from the scalp. At the Brigham, Cushing set Ernest Grey to work developing a preparation of fibrin - the natural constituent of a blood clot-to promote clotting, but the endeavor was unsuccessful because the material lacked thrombin, the clotting enzyme. ${ }^{4}$

Although Cushing possessed a variety of techniques to control bleeding during an operation, they all required time, and therefore his operations were excessively long. Maintaining hemostasis also forced him to end operations prematurely. He sometimes performed his operations in multiple stages. Removal of certain tumors was precluded because the risk of significant blood loss was too great.

An illustrative case demonstrates Cushing's difficulties with hemostasis. Meningioma surgery was particularly challenging due to the vascularity of these tumors, which often necessitated multiple operative sessions. A 62-yearold patient in 1922 was no exception. ${ }^{3}$ Although Cushing's previous method had been to remove meningiomas in one piece, he attempted the enucleation technique, which he had long used for acoustic tumors. After a decompression and exploratory operation 8 days earlier, Cushing had gone back in to find a tumor that was larger than expected. En bloc removal of the tumor would have caused too much damage to the surrounding brain. Piecemeal removal using a sharp spoon proved very tedious; after each fragment was removed, there was a delay to control new surface bleeding. The patient's blood pressure began to fall, forcing Cushing to stop and continue the procedure at a later session. He sewed the collapsed cavity shut and left the suture strings in hopes of pulling the 
mass forward in subsequent operations. Due to the fear of brain swelling, he could not replace the bone flap or resew the dura mater, and had to close the scalp with only a layer of rubber. A transfusion was necessary and several hours passed before the patient was out of danger. Due to the tension on the wound, healing was compromised and Cushing feared cerebral infection if the wound was reopened.

In the final session, 9 days later, Cushing drew the mass forward and brushed away the surrounding brain tissue until the tumor could finally be tilted out. Raw muscle (from another patient) was used to check the bleeding that occurred from the tumor's point of attachment, but the patient's blood pressure dropped again. Cushing closed the wound as best he could, but a cerebrospinal fluid fistula through the wound edges became apparent because the wound did not heal well. Not until 3 months after her admission had the patient sufficiently recovered to be discharged. The bone flap could not be replaced, which left her with an undesirable cosmetic deformity.

This operation was considered a success because the patient's vision was restored. She was well and active 5 years after the operation. The process used to remove the 204-g tumor was a major ordeal that included three hazardous operations totaling 7 hours in the operating room, and countless hours spent on the complicated dressing of the wound, from which cerebrospinal fluid was leaking. There were many procedures, however, that did not end as successfully, and many more patients in whom Cushing would not dare to perform an operation.

\section{Development of Electrosurgical Principles}

Little did Cushing know that the answer to his hemostasis dilemma was the incorporation of electrosurgical techniques into his practice. Electrosurgery, the use of the heat produced from the passage of high-frequency currents directly through tissue to produce a cutting and/or coagulating effect, was the logical fusion of cautery with electrophysiology. Although Cushing himself did not know much about this developing field prior to his interactions with Bovie, a review of the major scientific advances and the climate that surrounded medical applications of electrophysiology in the early 20th century helps place Cushing and Bovie's progress in perspective. Applications of the technology were not fully understood, and the fraudulent claims of some created an atmosphere of skepticism.

Although some physicians had made use of electric currents in surgery, the work was not very widely known by general surgeons at that time. The many different terms that were used in relation to electrosurgery in the first quarter of the 20th century caused a climate of confusion for many, especially those, like Cushing, who did not care to understand the physics behind the techniques. Not until Cushing's 1928 publication describing his accomplishments with Bovie's electrosurgical unit did the medical community accept electrosurgery, and "Bovie" became a common name in the operating room. Electrosurgical techniques further accelerated Cushing's triumph in conquering blood loss, changing the categorization of many formerly inoperable tumors to operable lesions.

\section{CONCLUSIONS}

Harvey Cushing possessed a pioneering spirit and unparalleled devotion to conquering neurosurgery's toughest obstacles. By 1910, Cushing had systematically reduced the number of his patients who experienced neurosurgery's primary complications-infection and the effects of intracranial pressure - to decrease mortality rates. His revolutionary incorporation of electrosurgical techniques into neurosurgery was no exception to his pattern of recognizing, embracing, and establishing the use of medical technologies with great potential.

\section{References}

1. Cushing H: Concerning a definite regulatory mechanism of the vaso-motor centre which controls blood pressure during cerebral compression. Bull Johns Hopkins Hosp 12:290-292, 1901

2. Cushing H: The control of bleeding in operations for brain tumors. With the description of silver "clips" for the occlusion of vessels inaccessible to the ligature. Ann Surg 54:1-19, 1911

3. Cushing H: The Meningiomas Arising From the Olfactory Groove and Their Removal by the Aid of Electro-surgery. Glasgow: Wylie, 1927

4. Fulton JF: Harvey Cushing: a Biography. Springfield, IL: Charles C Thomas, 1946

5. Greenblatt SH: The crucial decade: modern neurosurgery's definitive development in Harvey Cushing's early research and practice, 1900 to 1910. J Neurosurg 87:964-971, 1997

6. Horrax G: Some of Harvey Cushing's contributions to neurological surgery. J Neurosurg 54:436-447, 1981

7. Modlin IM: Surgical triumvirate of Theodor Kocher, Harvey Cushing, and William Halsted. World J Surg 22:103-113, 1998

8. Thomson EH: Harvey Cushing: Surgeon, Author, Artist. New York: Schuman, 1950

Manuscript received February 10, 2005.

Accepted in final form March 14, 2005.

Address reprint requests to: Aaron A. Cohen-Gadol, M.D., Department of Neurologic Surgery, Joseph 1-229, St. Mary's Hospital, 1216 Second Street SW, Rochester, Minnesota 55902. email: cohengadol.aaron@mayo.edu. 